Keywords: Self-rated health; Perceived health; Adolescents; Psychosocial functioning; Adolescent health.

\title{
Self-rated health, psychosocial functioning, and other dimensions of adolescent health in Central and Eastern European adolescents
}

\author{
Randy M. Page* \\ Jaromir Simonek ${ }^{\star \star}$ \\ Ferenc Ihász $z^{\star \star *}$ \\ lacob Hantiu ${ }^{\star \star * \star}$ \\ Martina Uvacsek $k^{\star \star \star \star \star}$ \\ Irén Kalabiska ${ }^{\star \star \star \star \star}$ \\ Renata Klarova ${ }^{\star \star \star \star \star \star}$
}

* Brigham Young University, Provo, Utah, USA

** University of Constantine the Philosopher, Nitra, Slovakia

*** West Hungary University, Gyor, Hungary

**** University of Oradea, Oradea, Romania

***** Semmelweis University, Budapest, Hungary

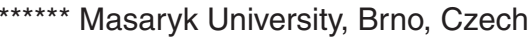

Republic

USA

CZECH REPUBLIC

\footnotetext{
ABSTRACT - Background and Objectives: Although studied extensively among adults, self-rated health (SRH) has not received the same research attention among adolescents. It has been suggested that SRH in adolescents may be a function of adolescents' overall sense of functioning and may reflect psychosocial functioning more so than in adults. The rating of health as poor by adolescents might be a somatic expression of life distress and may be connected with risky behaviors. Therefore, the purpose of this study was to investigate self-rated health (SRH) in Central and Eastern European (CEE) adolescents and determine its association with psychosocial functioning and other dimensions of adolescent health.
}

Methods: A survey was administered to 3,123 students in 34 secondary schools across CEE which included measures of SRH, psychosocial functioning (loneliness, hopelessness, shyness, perceptions of social status, self-rated happiness, and perception of physical 
attractiveness), and other dimensions of adolescent health (height/weight, physical activity, eating breakfast, sleep).

Results: More girls (19.4\%) than boys (11.3\%) rated themselves as "not healthy" and this was true in each of the six countries. Significant predictors of SRH in the logistic regression model were gender, country of residence, hopelessness, shyness, subjective social status-society, self-rated happiness, perception of physical attractiveness, vigorous physical activity, eating breakfast, overweight status, and usually get 7-8 hours or more sleep a night.

Conclusions: SRH appears to be associated with psychosocial functioning and other dimensions of adolescent health in CEE youth.

\section{Introduction}

Self-rated health ( $\mathrm{SRH})$ is frequently assessed by single item measurement of overall health status in which individuals rate their current health in qualitative terms (e.g., "excellent", "good", or "poor"). ${ }^{1}$ According to Idler and Benyamini ${ }^{2}$ the usefulness of SRH represents "an irreplaceable dimension of health status." Among adults, SRH has been found to be a valid measure of physical health status among adults and as a predictor of the use of health care services ${ }^{3}$, mortality and mortality ${ }^{4}$, and such risk behaviors as smoking, physical inactivity, lack of sleep, overweight, and alcohol consumption. ${ }^{5}$ However, it is unclear how evaluations of SRH are reached and in particular whether associations with health indicators (e.g., morbidity and mortality) reflect individuals' spontaneous assessment (dynamic) of health status and practices or reflect a more enduring self-concept (static) of health. ${ }^{6}$ Research by Ballis, Segall, and Chipperfield ${ }^{6}$ found that adults' evaluations of their general health are dynamic, reflecting changes in self-reported physical and mental health and health practices (spontaneous assessment). Yet, SRH also reflects an enduring self-concept of health to some degree in adults as evidenced by the fact that measurement of SRH independently predicted health status two years later.

SRH has not been studied extensively in adolescents, but also deserves strong research attention as an important factor in explaining adolescent health. ${ }^{1}$ Unfortunately only limited research has examined the stability of SRH in adolescent populations. Boardman ${ }^{1}$ examined SRH in two waves of the National Longitudinal Study of Adolescents in the U.S. and found SRH reported by adolescents to be a stable or static construct. He suggests that whereas among adults SRH is both a spontaneous health assessment and an enduring self-concept, among adolescents it "appears to be more appropriately characterized as an enduring self-concept."1

More recently, Breidablik, Meland, and Lydersen $^{7}$ studied the stability of SRH in a four-year longitudinal study of adolescents in Norway and found SRH to be a very stable construct through the four years of observation, with only a small percentage of the respondents changing their rating of subjective health. The proclivity for adolescents to view their health in a more static or enduring way 
may be a function of adolescent thinking tendency. Adolescents are often focused on the present and generally less able to make reflective past and projective future cognitions.

Zullig, Valois, Drane advocate that SRH in adolescents may reflect adolescents' overall sense of functioning, including psychosocial functioning, and quality of life ${ }^{8}$. Research by Wade, Prevalin, and Vingilis ${ }^{9}$ suggests that when adolescents rate their health as poor this may be a somatic expression of life distress and that SRH is affected by family financial situation, school achievement, selfesteem, and tobacco use. Studies have also found that adolescents who rate their health in a positive manner in comparison to those who rate their health negatively report higher levels of parental education, feel connected at school, perceive medical care is available when needed, live in a safe neighborhood, have a positive self-image, and are less likely to smoke. ${ }^{10}$ Other factors that have been implicated to affect SRH in adolescents include physical health problems and disability, child-parent relationships, school achievement, female gender, and higher body mass index (BMI). ${ }^{8,11,12}$

Adolescents form lifestyle patterns and perceptions of health during a life stage typically characterized by low rates of physical morbidity and mortality, rapid physical and psychosocial changes, and during a period when they become more introspective and aware of their bodies ${ }^{13}$. Vingilis, Wade, and Seeley ${ }^{14}$ assert that during adolescence, assessment of one's health is strongly influenced by impressions of psychosocial functioning. Therefore, psychological functioning may be an overriding determinant in adolescents' expression of $\mathrm{SRH}^{8}$. The purpose of the current study was to investigate self-rated health (SRH) in a sample of Central and Eastern European adolescents and determine whether those rating themselves as not healthy differed from those with the ratings of healthy and very healthy on measures of psychosocial functioning (loneliness, hopelessness, shyness, perceptions of social status, self-rated happiness, and perception of physical attractiveness) and other dimensions of adolescent health (height/weight, physical activity, eating breakfast, sleep).

\section{Methods}

\section{Sample and Data Aggregation}

The sample for this study includes high school students from ten Hungarian, six Slovakian, five Romanian, eight Ukrainian, four Polish, and one Czech Republic school. The Hungarian schools were located in the following cities with the number of schools in each city identified in parenthesis: Gyor (4), Mosonmagyarovar (3), Papa (1), Pecs (1), and Miskolc (1). In Slovakia schools were from the following cities Bratislava(1), Nitra(3), Sahy (1), and Levice (1). Polish schools were located in Warsaw (2) and Wroclaw (2). The five Romanian schools were in the city of Oradea and the four Ukrainian schools were located in Mukachevo. The one school in the Czech Republic was located in Brno.

In each of these schools, an identical survey instrument was administered to collect local data about adolescent health and wellbeing of students taking physical education classes. These surveys were conducted by faculty members from five different Central European universities during the 2004-2006 academic years for the overall purpose of assessing student health and well-being. Although the data was collected in physical education classes, a uniform sampling procedure across the countries, cities, and schools 
represented in the sample was not employed. Instead, the students who completed surveys within each country, city, and school represent samples of convenience of those enrolled in selected physical education classes. Despite, the lack of a systematic sampling procedure, it was determined that there would be value in pooling this data from an identical survey administered across these six countries, 13 cities, and 34 schools into a single data set composed of 3,123 high school students attending primarily public (state-supported) schools from a mix of urban and rural areas in Central-Eastern Europe. This aggregation of data created a unique opportunity to study a large cross-section of high school students living throughout Central and Eastern Europe. However, the lack of sampling methodology equivalency across the various schools and countries is problematic because the data has limited representativeness of the various geographical jurisdictions.

In the data pool, there were 1,392 boys, 1,706 girls, and 25 subjects who did not report their gender. The mean age of subjects was 16.6 years $(S D=25)$. Table I provides subject characteristics by countries represented in the data pool.

Table I

Data Pool and Subject Characteristics by Country

\begin{tabular}{|c|c|c|c|c|c|c|}
\hline & Hungary & Ukraine & Slovakia & Romania & Poland & $\begin{array}{c}\text { Czech } \\
\text { Republic }\end{array}$ \\
\hline No. of subjects & 915 & 913 & 333 & 336 & 324 & 300 \\
\hline No. of schools & 10 & 8 & 6 & 5 & 4 & 1 \\
\hline Location & $\begin{array}{c}\text { Gyor, } \\
\text { Mosonmagyarovar } \\
\text { Papa, Pecs, Miskolc }\end{array}$ & Mukachevo & $\begin{array}{l}\text { Bratislava, } \\
\text { Nitra, Levice }\end{array}$ & Oradea & $\begin{array}{l}\text { Warsaw, } \\
\text { Wroclaw }\end{array}$ & Brno \\
\hline Mean age & $\begin{array}{c}16.4 \\
(S D=1.22)\end{array}$ & $\begin{array}{c}16.4 \\
(S D=1.16)\end{array}$ & $\begin{array}{c}16.6 \\
(S D=1.23)\end{array}$ & $\begin{array}{c}17.2 \\
(S D=0.95)\end{array}$ & $\begin{array}{c}17.2 \\
(S D=0.57)\end{array}$ & $\begin{array}{c}16.9 \\
(S D=1.22)\end{array}$ \\
\hline \multicolumn{7}{|c|}{ 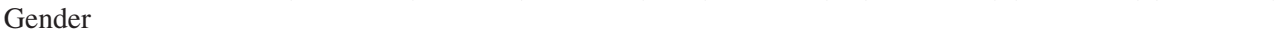 } \\
\hline Males & 449 & 439 & 111 & 157 & 124 & 112 \\
\hline Females & 463 & 460 & 222 & 178 & 196 & 186 \\
\hline Not reporting & 4 & 14 & 0 & 1 & 4 & 2 \\
\hline
\end{tabular}

\section{Survey Instrumentation and Data Collection}

A survey instrument containing the exact items was administered across all 34 schools included in the sample. Surveys were translated from English into the representative languages of each country included in the study: Hungarian, Czech, Romanian, Slovakian, Polish, and Ukrainian. Translations were conducted by faculty members from the involved universities who were fluent in English and who also conducted back translation into English to help control for variation in questionnaire equivalency. Survey instruments were passed out to students in class by physical education teachers. Written instructions on the survey alerted students not to place their names on the survey forms, that their participation was voluntary, and to answer the questions honestly and accurately. The survey took 10-15 minutes for most stuof class time for the administration of the survey. Questionnaires were placed in envelopes by students after completion and not handed directly to school teachers or school personnel. dents to complete and took about 20 minutes 
The survey instrument for this study included a single-item measure of self-rated health (SRH), five measures that relate to psychosocial functioning (loneliness, hopelessness, shyness, perceptions of social status, and self-rated happiness) and other dimensions of adolescent health. SRH was assessed by asking "How healthy would you say that you are?" with response options of "very healthy," "healthy," or "not healthy." This measure of SRH is the same as that used in the World Health Organization collaborative health behavior in school aged children study ${ }^{15,16}$. The use of a single item measurement to assess SRH is consistent with most research involving this indicator of overall health status ${ }^{1}$. Self-rated health among adolescents has been found to be a stable and consistent measure over repeated observations ${ }^{15}$.

Loneliness was measured by the revised U.C.L.A. Loneliness Scale (R-UCLA), a unidimensional index of loneliness, made up of 20 Likert-type items reflecting satisfaction and dissatisfaction with life and social relationships. Psychometric analyses of this scale have found it to be a valid and highly reliable measure across various populations and cross-culturally ${ }^{17}$. In the current sample we found acceptable internal consistency for this scale in this sample with a Cronbach's alpha coefficient of 0.82 .

Hopelessness was measured with the Beck Hopelessness Scale, a 20-item, true-false inventory designed to measure lack of hope about the future by assessing pessimistic cognitions concerning oneself and one's future life. This scale has been used frequently with adolescent and young adult samples is established as a reliable and valid measure of the negative expectancies which are often very resistant to change that are descriptive of hopelessness ${ }^{18}$. In the current sample we found acceptable internal consistency relia- bility with an alpha reliability coefficient (Cronbach's alpha) on the scale of 0.74 .

Shyness was measured by the Cheek and Buss Shyness Scale which is composed of nine items operationalizing shyness as the discomfort and inhibition that may occur in the presence of others. Heisner, Turner, and Beidel ${ }^{19}$ have reported adequate convergent validity for this scale as well as high test-reliability. We found an acceptable alpha reliability coefficient (Cronbach's alpha) on the shyness scale with a coefficient of 0.74 .

Perceptions of social status were measured by the MacArthur Scale of Subjective Social Status - Youth Version ${ }^{20}$. This measures uses an easy pictorial format by presenting a "social ladder" and asks respondents to place a mark on the rung where they feel they stand. It is composed of two separate ladders one measuring subjective status in society and another measure subjective social status in the school. Scores on each ladder can range from 1 (lowest social status) to 10 (highest social status). Goodman et al. ${ }^{20}$ report excellent two-month test reliability with intraclass correlation coefficients of 0.83 for the society ladder and 0.81 for the school ladder.

Self-rated happiness is an item, like selfrated health, found on the WHO collaborative study instrument. It is a single-item measure that asks respondents "How do you feel about your life at present?" and includes the following response options: "I feel very happy," "I feel quite happy," "I don't feel very happy," and "I'm not happy at all."

Items modeled after the U.S. Centers for Disease Control and Prevention's (CDC) Youth Risk Behavior Survey ${ }^{21}$ were primarily used as the physical activity measures in this study and included days of participating in the past week of vigorous physical activity (makes you sweat and breathe hard for at 
least 20 minutes), days of participating in muscle-strengthening activity, number of sports teams playing on in past 12 months, amount of time involved in physical activity outside of school, and a summary measure of physical activity. The use of self-report measures in studies of adolescent health behavior is well-established. The Youth Risk Behavior Survey, which provides the physical activity items in the present study, has a kappa statistic reliability of $61-80 \%$ or higher and an alpha reliability of $0.79 .{ }^{22}$ However, as expected, there are general limitations of self-report items and physical activity items have been found to be less reliable that adolescent self-reports of tobacco use, substance use, and sexual activity. ${ }^{23,24}$

The authors added items about sleeping habits and eating breakfast on the survey questionnaire that were developed by the investigators. Sleep habits were assessed by asking students "how many hours of sleep do you usually get" and "do you usually get enough sleep?" Eating breakfast habit was assessed by asking on how many days in the past week breakfast was eaten.

Body mass index $\left(\mathrm{kg} / \mathrm{m}^{2}\right)$ was calculated from self-reported height and weight and then applied to international cutoff points by sex and age to determine overweight and obesity status. The cutoff points used were those established by the Childhood Obesity Working Group of International Task Force on Obesity (IOTF) and are often used in public health studies as an international reference of overweight and obesity for children and adolescents aged 2-18 years ${ }^{25}$.

A final measure was perception of physical attractiveness. Respondents were asked to rate their physical activity by marking on a continuum ranging from extremely unattractive $^{1}$ to extremely attractive ${ }^{9}$.

\section{Analysis of Data}

A logistic regression analysis was performed with self-rated health (SRH) as the dependent variable and the following included as predictor variables in the model: gender, country of residence, loneliness, shyness, hopelessness, perception of social status-society, perception of social status-school, vigorous physical activity, muscle strengthening activity, number of sports teams played on, eating breakfast, overweight status, obesity status, usually get 7-8 hours or more sleep a night, and usually get enough sleep. Mean scores for continuously-scored variables and percentages for categorical variables were calculated according to level of self-rated health ("very health," "healthy," and "not healthy) and Analysis of variance (ANOVA) and Chi-square tests were used to determine whether there were differences on these characteristics between the three groups. Statistical tests were computed with SAS version 9.1 for Windows.

\section{Results}

Table II displays self-rated health (SRH) according to the gender of the survey respondents. Overall, boys and girls differed significantly on SRH $\left(\chi^{2}=69.6, \mathrm{p}<0.0001\right)$, with a higher proportion of boys $(22.2 \%)$ than girls $(12.9 \%)$ reporting their health as very high and a lower proportion of boys (11.3\%) reporting that they were not healthy than girls (19.4\%). Table II also shows the distribution of students from each of the countries by gender and level of SRH. In each country, boys were more likely than girls to rate their health as "very healthy" than girls. Self-rated health appeared to be highest among Czech, Polish, Slovakian, and Romanian students than among Hungarian and Ukrainian students. 
Table II

Level of Self-Rated Health by Gender

\begin{tabular}{|c|c|c|c|c|}
\hline & $\begin{array}{l}\text { Mean } \\
M(S D)\end{array}$ & $\begin{array}{c}\text { Very Healthy } \\
\%(f)\end{array}$ & $\begin{array}{l}\text { Healthy } \\
\%(f)\end{array}$ & $\begin{array}{c}\text { Not Healthy } \\
\%(f)\end{array}$ \\
\hline \multicolumn{5}{|c|}{ Total Sample ${ }^{\mathrm{a}}$} \\
\hline Boys & $1.11(0.57)$ & $22.2(306)$ & $66.5(917)$ & $11.3(156)$ \\
\hline Girls & $0.93(0.56)$ & $12.9(219)$ & $67.7(1145)$ & $19.4(328)$ \\
\hline \multicolumn{5}{|c|}{ Hungarian Students ${ }^{\mathrm{b}}$} \\
\hline Boys & $0.99(0.57)$ & $16.1(72)$ & $67.2(301)$ & $16.7(75)$ \\
\hline Girls & $0.79(0.51)$ & $5.0(23)$ & $69.2(319)$ & $25.8(119)$ \\
\hline \multicolumn{5}{|c|}{ Czech Students ${ }^{\mathrm{c}}$} \\
\hline Boys & $1.52(0.57)$ & $56.5(61)$ & $39.8(43)$ & $3.7(4)$ \\
\hline Girls & $1.31(0.53)$ & $34.2(63)$ & $62.5(115)$ & $3.3(6)$ \\
\hline \multicolumn{5}{|c|}{ Slovakian Students $^{\mathrm{d}}$} \\
\hline Boys & $1.26(0.49)$ & $33.3(36)$ & $60.2(65)$ & $6.5(7)$ \\
\hline Girls & $1.10(0.54)$ & $19.9(43)$ & $69.9(151)$ & $10.2(22)$ \\
\hline \multicolumn{5}{|c|}{ Romanian Students ${ }^{\mathrm{e}}$} \\
\hline Boys & $1.26(0.49)$ & $29.0(45)$ & $68.4(106)$ & $2.6(4)$ \\
\hline Girls & $1.02(0.31)$ & $6.2(11)$ & $89.9(160)$ & $3.9(7)$ \\
\hline \multicolumn{5}{|c|}{ Polish Students ${ }^{\mathrm{f}}$} \\
\hline Boys & $1.38(0.55)$ & $41.1(51)$ & $55.6(69)$ & $3.2(4)$ \\
\hline Girls & $1.15(0.64)$ & $28.9(56)$ & $57.2(111)$ & $13.9(27)$ \\
\hline \multicolumn{5}{|c|}{ Ukrainian Students ${ }^{\mathrm{g}}$} \\
\hline Boys & $0.95(0.48)$ & $9.4(41)$ & 76.4 (333) & $14.2(62)$ \\
\hline Girls & $0.72(0.55)$ & $5.0(23)$ & $63.0(289)$ & $32.0(147)$ \\
\hline
\end{tabular}

${ }^{a}$ Boys and girls differed significantly on self-rated health $\left(\chi^{2}(2)=69.6, p<0.0001\right)$.

${ }^{\mathrm{b}}$ Boys and girls differed significantly on self-rated health $\left(\chi^{2}(2)=35.9, p<0.0001\right)$.

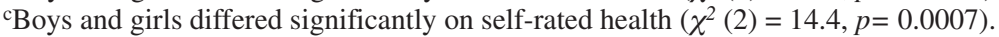

${ }^{\mathrm{d}}$ Boys and girls differed significantly on self-rated health $\left(\chi^{2}(2)=7.4, p=0.0241\right)$.

${ }^{\mathrm{e} B o y s}$ and girls differed significantly on self-rated health $\left(\chi^{2}(2)=30.9, p<0.0001\right)$.

${ }^{\mathrm{f} B o y s}$ and girls differed significantly on self-rated health $\left(\chi^{2}(2)=12.3, p=0.0021\right)$.

${ }^{g}$ Boys and girls differed significantly on self-rated health $\left(\chi^{2}(2)=42.2, p<0.0001\right)$.

Logistic regression results are presented in Table III. Significant predictors of SRH in the regression model were gender, country of residence, hopelessness, shyness, subjective social status-society, self-rated happiness, perception of physical attractiveness, vigorous physical activity, eating breakfast, overweight status, and usually get 7-8 hours or more sleep a night.

Tables IV and V display values on psychosocial functioning and health-related variables by level of SRH and associated univari- ate statistical tests of difference. Significant main effects $(p<0.05)$ of SRH level or Chisquare association with SRH level were found for all of the dependent measures among boys, except for self-rated happiness and number of sports teams played on in the past 12 months. Among girls, significant main effects of SRH level or Chi-square association with SRH on the dependent measures were found among girls for all variables except muscle strengthening activity, number of sports teams played on, and obesity status. 
Table III

Logistic Regression Results for Psychosocial Functioning, Health-Related Variables, and Other Variables Paramter Estimate Wald Chi-Square $\quad \mathrm{Pr}>\mathrm{ChiSq} \quad$ Odds Ratio (CI)

\begin{tabular}{lcrrr}
\hline Gender & & & & \\
$\quad$ Female (Reference) & - & - & - \\
$\quad$ Male & 0.71 & 54.77 & $<0.0001$ & $2.04(1.69)$ \\
Country of Residence & & & & \\
$\quad$ Ukraine (Reference) & - & - & & - \\
Hungary & 0.31 & 4.85 & 0.0276 & $1.36(1.03,1.79)$ \\
Czech Republic & 2.69 & 222.14 & $<0.0001$ & $14.82(10.39,21.12)$ \\
Slovakia & 2.10 & 124.84 & $<0.0001$ & $7.47(5.25,10.63)$ \\
Romania & 1.65 & 100.12 & $<0.0001$ & $5.22(3.78,7.22)$ \\
Poland & 2.16 & 138.98 & $<0.0001$ & $8.70(6.07,12.46)$ \\
Loneliness & -0.01 & 1.08 & 0.2977 & $0.99(0.98,1.01)$ \\
Hopelessness & -0.06 & 13.7 & 0.0002 & $0.94(0.96,0.99)$ \\
Shyness & -0.02 & 7.49 & 0.0062 & $0.98(0.96,0.99)$ \\
Subjective social status (SSS) - society & 0.08 & 7.65 & 0.0057 & $1.10(1.02,1.16)$ \\
Subjective social status (SSS) -school & -0.01 & 0.28 & 0.5945 & $0.98(0.93,1.04)$ \\
Self-rated happiness & -0.33 & 18.93 & $<0.0001$ & $0.72(0.62,0.83)$ \\
Perception of physical attractiveness & 0.16 & 23.59 & $<0.0001$ & $1.18(1.10,1.25)$ \\
$\quad$ Vigorous physical activity & 0.15 & 28.84 & $<0.0001$ & $1.17(1.10,1.23)$ \\
Muscle strengthening activity & 0.03 & 1.08 & 0.2967 & $1.03(0.98,1.08)$ \\
Number of sports teams played on & 0.01 & 0.58 & 0.44 & $1.01(0.98,1.06)$ \\
Eating breakfast & 0.04 & 5.91 & 0.0151 & $1.04(1.01,1.07)$ \\
Overweight & 0.41 & 5.55 & 0.0185 & $1.51(1.07,2.12)$ \\
Obese & -0.32 & 0.31 & 0.5733 & $0.72(0.24,2.21)$ \\
Usually get 7-8 hours or more sleep a night & & & & \\
$\quad$ No (reference) & - & - & - & - \\
Yes & -0.18 & 3.89 & 0.0485 & $0.83(0.69,0.99)$ \\
Hours of sleep usually get & -0.00 & 0.00 & 0.9806 & $1.00(0.88,1.13)$ \\
\hline
\end{tabular}

\section{Discussion}

Research among adolescents suggests more positive self-evaluation of health by boys than girls ${ }^{26,27}$ and our findings among this sample of Central and Eastern European youth align with those previous findings. We found a significantly higher proportion of boys than girls rating their health as very healthy, and a higher proportion of girls rating themselves as not healthy. Further, we found this finding across all six of the countries represented in our sample. Tremblay, Dahinten, and Kohen ${ }^{28}$ suggest that this gender difference showing lower selfperceived health among girls may be connected to young female concerns about reproduc- tion issues, higher levels of emotional distress, and/or greater preoccupation with matters such as appearance, body weight, and social relationships.

A study by Torsheim et al..$^{15}$ used the identical item that we used to assess SRH in a study of adolescents across 27 European and North American countries. They reported that across the countries that $4.6 \%$ for boys and $8.2 \%$ for girls self-reported their health as "not healthy." Unfortunately, they did not report the percentages of students in specific countries, but their results found substantial inequalities in subjective health across the countries related to the distribution of family material resources (e.g., fam- 
Table IV

Psychosocial Functioning and Health-Related Variables for Boys According to Level of Self-Rated Health

\begin{tabular}{|c|c|c|c|c|}
\hline & Very Healthy & Healthy & Not Healthy & Significance \\
\hline Continuously-scaled variables & $\mathrm{M}(\mathrm{SD})$ & $\mathrm{M}(\mathrm{SD})$ & $\mathrm{M}(\mathrm{SD})$ & $F$ ratio $(d f), p$ \\
\hline Loneliness & $37.3(7.9)$ & $39.2(7.4)$ & $41.9(8.7)$ & $\begin{array}{c}\mathrm{F}(2,1230)= \\
16.3, p<0.0001\end{array}$ \\
\hline Shyness & $12.0(6.9)$ & $13.2(6.2)$ & $15.3(7.8)$ & $\begin{array}{c}\mathrm{F}(2,1311)= \\
12.4, p<0.0001\end{array}$ \\
\hline Hopelessness & $4.9(3.6)$ & $5.3(3.1)$ & $6.2(4.2)$ & $\begin{array}{l}\mathrm{F}(2,1286)= \\
6.8, p=0.0012\end{array}$ \\
\hline Subjective social status (SSS) - society & $6.7(1.7)$ & $6.2(1.6)$ & $5.8(1.6)$ & $\begin{array}{c}\mathrm{F}(2,1343)= \\
14.7, p<0.0001\end{array}$ \\
\hline Subjective social status (SSS) - school & $6.9(1.8)$ & $6.6(1.9)$ & $5.9(1.9)$ & $\begin{array}{c}\mathrm{F}(2,1341)= \\
11.6, p<0.0001\end{array}$ \\
\hline Self-rated happiness & $3.3(0.8)$ & $3.4(0.7)$ & $3.3(0.8)$ & $\begin{array}{l}\mathrm{F}(2,1338)=0.7 \\
p=0.4858(\mathrm{NS})\end{array}$ \\
\hline Perception of physical attractiveness & $6.6(1.6)$ & $6.0(1.4)$ & $5.5(1.9)$ & $\begin{array}{c}\mathrm{F}(2,1359)= \\
29.2, p<0.0001\end{array}$ \\
\hline Vigorous physical activity & $4.0(2.0)$ & $3.2(1.9)$ & $2.2(1.9)$ & $\begin{array}{c}\mathrm{F}(2,1367)= \\
46.0, p<0.0001\end{array}$ \\
\hline Muscle strengthening activity & $2.9(2.2)$ & $2.6(2.1)$ & $1.8(2.0)$ & $\begin{array}{c}\mathrm{F}(2,1372)= \\
12.6, p<0.0001\end{array}$ \\
\hline Number of sports teams played on & $3.2(2.6)$ & $3.2(2.7)$ & $2.7(2.8)$ & $\begin{array}{l}\mathrm{F}(2,1362)=2.1 \\
p=0.1201(\mathrm{NS})\end{array}$ \\
\hline Activity index & $13.0(5.9)$ & $11.8(5.6)$ & $9.1(5.3)$ & $\begin{array}{c}\mathrm{F}(2,1317)= \\
23.8, p<0.0001\end{array}$ \\
\hline Eating breakfast & $4.2(2.8)$ & $4.1(2.8)$ & $3.5(2.5)$ & $\begin{array}{c}\mathrm{F}(2,1372)=3.8 \\
\quad p=0.0230\end{array}$ \\
\hline Categorically-scaled variables & $\%(f)$ & $\%(f)$ & $\%(f)$ & $\chi^{2}(d f), p$ \\
\hline Overweight & $9.5(29)$ & $11.3(103)$ & $18.6(29)$ & $\begin{array}{c}\chi^{2}(2)=8.7 \\
p=0.0124\end{array}$ \\
\hline Obese & $1.0(3)$ & $1.2(11)$ & $3.9(3)$ & $\begin{array}{l}\chi^{2}(2)=7.1 \\
p=0.0286\end{array}$ \\
\hline $\begin{array}{l}\text { Usually get 7-8 hours or more sleep } \\
\text { a night }\end{array}$ & $81.1(248)$ & $79.7(729)$ & $71.1(111)$ & $\begin{array}{l}\chi^{2}(2)=6.8 \\
p=0.0332\end{array}$ \\
\hline Usually get enough sleep & $55.6(170)$ & 48.7 (443) & $39.9(61)$ & $\begin{array}{c}\chi^{2}(2)=10.3 \\
p=0.0057\end{array}$ \\
\hline
\end{tabular}

ily affluence, average household income per capita). Torsheim et al. ${ }^{15}$ noted that $11 \%$ of the total variation in SRH was due to country differences and determined that for $95 \%$ of the countries examined, the percentage of boys reporting "not healthy" would fall between $1.4 \%$ and $14.4 \%$ for boys, and between $2.5 \%$ to $23.2 \%$ for girls. We found variation across the countries in our study in the percent of students in our study reporting being "not healthy." The highest percentages were among Ukrainian and Hungarian students, and lowest among Czech, Romanian, and Polish students. Many factors may be involved in explaining country and individual differences in SRH such as socioeconomic status, inequalities in income distribution, family income and worry about family finances, presence of a chronic condition or physical health problem, health behaviors, body weight and appearance concerns, social relationships, school achievement, and psy- 
Table V

Psychosocial Functioning and Health-Related Variables for Girls According to Level of Self-Rated Health

\begin{tabular}{|c|c|c|c|c|}
\hline & Very Healthy & Healthy & Not Healthy & Significance \\
\hline Continuously-scaled variables & $\mathrm{M}(\mathrm{SD})$ & $\mathrm{M}(\mathrm{SD})$ & $\mathrm{M}(\mathrm{SD})$ & $F$ ratio $(d f), p$ \\
\hline Loneliness & $37.3(8.2)$ & $38.1(7.5)$ & $40.9(8.3)$ & $\begin{array}{c}\mathrm{F}(2,1593)= \\
19.9, p<0.0001\end{array}$ \\
\hline Shyness & $12.7(6.6)$ & $13.8(6.4)$ & $12.7(7.5)$ & $\begin{array}{c}\mathrm{F}(2,1645)= \\
13.7, p<0.0001\end{array}$ \\
\hline Hopelessness & $4.6(3.0)$ & $5.0(3.1)$ & $6.5(3.7)$ & $\begin{array}{c}\mathrm{F}(2,1588)= \\
28.3, p<0.0001\end{array}$ \\
\hline Subjective social status (SSS) - society & $6.5(1.6)$ & $6.3(1.6)$ & $5.9(1.4)$ & $\begin{array}{c}\mathrm{F}(2,1667)= \\
12.1, p<0.0001\end{array}$ \\
\hline Subjective social status (SSS) - school & $7.0(1.6)$ & $6.8(1.9)$ & $6.4(1.9)$ & $\begin{array}{c}\mathrm{F}(2,1663)=8.0, \\
p=0.0004\end{array}$ \\
\hline Self-rated happiness & $3.3(0.7)$ & $3.2(0.7)$ & $3.1(0.7)$ & $\begin{array}{c}\mathrm{F}(2,1659)=6.5, \\
p=0.0016\end{array}$ \\
\hline Perception of physical attractiveness & $6.2(1.3)$ & $5.9(1.4)$ & $5.6(1.5)$ & $\begin{array}{c}\mathrm{F}(2,1678)=9.5 \\
p<0.0001\end{array}$ \\
\hline Vigorous Physical Activity & $2.8(1.7)$ & $2.4(1.7)$ & $2.0(1.7)$ & $\begin{array}{c}\mathrm{F}(2,1681)= \\
16.1, \mathrm{p}<0.0001\end{array}$ \\
\hline Muscle Strengthening Activity & $1.9(2.1)$ & $1.8(1.9)$ & $1.6(2.0)$ & $\begin{array}{l}\mathrm{F}(2,1685)=1.5 \\
p=0.2141(\mathrm{NS})\end{array}$ \\
\hline Number of sports teams played on & $2.2(2.4)$ & $2.2(2.6)$ & $2.5(2.7)$ & $\begin{array}{c}\mathrm{F}(2,1681)=1.1, \\
\quad p=0.3299\end{array}$ \\
\hline Activity index & $9.4(5.5)$ & $8.6(4.7)$ & $8.1(5.0)$ & $\begin{array}{c}\mathrm{F}(2,1641)=4.3, \\
p=0.0139\end{array}$ \\
\hline Eating Breakfast & $4.3(2.8)$ & $4.3(2.8)$ & $4.1(2.8)$ & $\begin{array}{c}\mathrm{F}(2,1687)=4.7 \\
p=0.0088\end{array}$ \\
\hline Categorically-scaled variables & $\%(f)$ & $\%(f)$ & $\%(f)$ & $\chi^{2}(d f), p$ \\
\hline Overweight & $2.3(5)$ & $4.7(54)$ & $5.5(18)$ & $\begin{array}{c}\chi^{2}(2)=3.3 \\
p=0.1874(\mathrm{NS})\end{array}$ \\
\hline Obese & $0.0(0)$ & $0.2(2)$ & $0.0(0)$ & $\begin{array}{c}\chi^{2}(2)=0.0 \\
p=0.6201(\mathrm{NS})\end{array}$ \\
\hline \multicolumn{2}{|c|}{ Usually get 7-8 hours or more sleep a night76.3 (167) } & $81.5(927)$ & $76.2(250)$ & $\begin{array}{c}\chi^{2}(2)=6.2 \\
p=0.0440\end{array}$ \\
\hline Usually get enough sleep & $49.5(108)$ & $52.1(593)$ & $41.6(136)$ & $\begin{array}{c}\chi^{2}(2)=11.2 \\
p=0.0036\end{array}$ \\
\hline
\end{tabular}

chological health status (e.g., self-esteem, stress, depression) $)^{14-16}$.

Vingilis, Wade, and Seeley ${ }^{14}$ postulate that psychosocial functioning during adolescence is a major factor shaping a young person's appraisal of personal health status and, may thus more represent an adolescent's overall sense of psychosocial functioning than their physical functioning. Thus, our findings showing a distinct pattern of psychosocial distress or poor psy- chosocial functioning among the adolescents in the sample who rated themselves as "not healthy" substantiate their postulation. Hopelessness and shyness were significant predictors of SRH in the logistic regression model. Further, adolescents of both genders scored significantly higher on measures of loneliness, shyness, and hopelessness, and lower on perception of social status. Also girls, but not boys, who rated themselves as "not healthy" scored lower on self-rated 
happiness. It has been explained that young people may tend to relate general life difficulties to health problems and reflect underlying patterns of expressing life distress in physical rather than psychological terms. There is some evidence that adolescents give greater emphasis to psychological functioning when reporting health status than do adults ${ }^{8}$. Whereas adults may see psychological functioning and physical functioning as two distinct constructs when reporting health status, adolescents instead may view health status more in relationship to life distress. Clearly, the findings showing higher loneliness and hopeless scores are concerning in light of the fact that hopelessness and loneliness are cognitive variables associated with increased risk for suicide, along with low self esteem, poor problem-solving skills, and external locus of control ${ }^{29,30}$. Shyness, and lowered feelings of happiness and perception of social status are also concerning because they also indicate problems in psychosocial functioning for a young person.

Because previous research has found a relationship between SRH and health-related behavior among North American and Western European adolescents ${ }^{31}$ we were not surprised to find similar results in our sample of CEE adolescents. In general, we found that "not healthy" adolescents were less likely to participate in vigorous physical activity, eat breakfast, get 7-8 hours of sleep, and usually get enough sleep. In addition to psychological functioning, it has been suggested that adolescents may use health-related behaviors such as physical activity as a frame of reference for $\mathrm{SRH}^{32,33}$. Physical activity is an important lifestyle dimension of adolescent health because it is associated with several health benefits, including the prevention of overweight and obesity $^{34}$. Sleep is important to health and perception of health; it plays a significant role in predicting depressive symptoms and self-esteem during adolescence and "adolescent moodiness," which often negatively influences coping skills and relationships with peers and adults, has been linked to insufficient sleep ${ }^{35,36}$. Inadequate nutrition (often complicated by skipping breakfast) likely negatively impacts learning problems, as hunger affects adolescents' concentration and ultimately their ability to learn ${ }^{37}$. More research is needed to address the relationship between adolescent dietary patterns, including consumption of fruits and vegetables and lowered fat intake, and SRH because so few studies have addressed this important area of adolescent health to date ${ }^{33}$.

Meland, Haugland, and Breidablik ${ }^{16}$ suggest that physical appearance and body image may influence adolescents' perceived or selfrated health because "adolescents who depart from socially determined norms of attractiveness or individual ideals' perceived current body size and perceived ideal body size". Our study results reflected this thinking showing that adolescents with a poor perception of health ("not healthy") correspondingly rated their physical attractiveness lower than those with higher perceptions of health ("very healthy"). There was also the finding among boys showing a higher prevalence of overweight and obesity among those who rated their health as "not healthy." Meland, Haugland, and Breidablik ${ }^{16}$ caution that health professionals need to be careful about the messages they send to adolescents about body weight because if there is too much emphasis on an "ideal" or "perfect" body image this may contribute to health worries and thus undermine young people's subjective health.

Our findings showing a pattern of poor psychological functioning and health behavior risk warrants attention and supports further study in this area. One approach at interven- 
tion includes health education and health counseling strategies, which build self-esteem and self-confidence among adolescents perceiving themselves as "not healthy" 16 . While these interventions may improve perceptions of health, they are unlikely to improve longterm indicators of SRH in adolescents, namely factors such as socioeconomic status, family income, school achievement, chronic condition or physical health problem, body weight and appearance concerns, social relationships, and psychological health status.

\section{Limitations}

It is important again to highlight that this study suffers from sampling limitations. The data in this study was composed of survey administrations designed to collect local information about adolescent health and is representative primarily of the individual high schools and localities from which it was collected. This data was pooled together to meet the purposes of this study and therefore was not designed to be representative of Central and Eastern adolescents. The data pool does, however, represent a large cross section of youth living in this region of the world and presents the opportunity to study the relationship between SRH, psychosocial functioning, and other dimensions of adolescent health.

In the current study we used a popular and frequently use SRH item with three response options: "very healthy," "healthy," and "not healthy." It should be noted, however, that much of the research cited in this study uses different items to measure SRH with the following five response options: "excellent," "very good," "good," "fair," and "poor." These measurement items are therefore, not necessarily equivalent and variations in findings could occur because of the inconsistency in items used in this area of research. Another measurement issue of importance in the current study is the equivalency of questionnaires and questionnaire items given that the survey was translated from English into six different languages. This raises questions about the cultural sensitivity of the questions/instruments.

The study is cross-sectional in nature and this makes it impossible to determine casuality and direction between associated measures. However, despite the limitations of this study, our findings advance the literature on SRH among adolescents and set the stage for future research in other adolescent populations.

\section{References}

1. Boardman JD. Self-rated health among U.S. adolescents. J Adolesc 2006; 38: 401-408.

2. Idler EL, Benyamini Y. Self-rated health and mortality: A review of twenty-seven community studies. J Health Soc Behav 1997; 38: 21-37.

3. Bierman AS, Bubolz TA, Fisher ES, Wasson JH. How well does a single question about health predict the financial health of Medicare managed care plans? Eff Clin Pract 1999; 2: 56-62.

4. Benyamini Y, Idler EL. Community studies reporting association between self-rated health and mortality: Additional samples, 1995 to 1998. Res Aging 1999; 21: 392-401.

5. Segovia J, Bartlett RF, Edwards AC. The association between self-assessed health status and individual health practices. Can J Pub Health 1989; 80: 32-37.

6. Ballis DS, Segall A, Chipperfield JG. Two views of self-rated general health status. Soc Sci Med 2003; 56: 203-217.

7. Breidablink HJ, Meland E, Lydersen S. Self-rated health during adolescence: Stability and predictors of change (Young-HUNT study, Norway). Eur J Public Health 2008; doi:10.1093/eurpub/ckn111.

8. Zullig KJ, Valois RF, Drane JW. Adolescent distinctions between quality of life and self-rated health in quality of life research. Health Qual Life Outcomes 2005; 3(64): 1-9. 
9. Wade TJ, Prevalin DJ, Vingilis E. Revisiting student self-rated physical health. J Adolesc 2000; 23: 785-791.

10. Call KT, Nonnemaker J. Socioeconomic disparities in adolescent health: contributing factors. Ann N Y Acad Sci 1999; 896: 352-355.

11. Needham BL, Crosnoe R, Muller C. Academic failure in secondary school: The inter-related role of health problems and educational context. Soc Probl 2004; 51(4): 569-586.

12. Vingilis E, Wade TJ, Seeley S. Predictors of adolescent self-rated health. Can J Pub Health 2002; 93: 193-197.

13. Smetana JG, Campione-Barr N, Metzger A. Adolescent development in interpersonal and societal contexts. Annu Rev Psychol 2006; 57: 255-284.

14. Vingilis E, Wade TJ, Seeley J. What factors predict adolescent self-rated health and health care utilization? Community Health Reporter (Research Update) 2000; Fall: 1-3.

15. Torsheim T, Currie C, Boyce W, Samdal. Country material distribution and adolescents' perceived health: Multilevel study of adolescents in 27 countries. J Epidemiol Community Health 2006; 60: 156-161.

16. Meland E, Haugland S, Breidablik HJ. Body image and perceived health in adolescence. Health Educ Res 2007; 22(3): 342-350.

17. Russell DW. UCLA Loneliness Scale (Version 3): Reliability, validity, and factor structure. J Pers Assess 1996; 66(1): 20-40.

18. Langhinrichsen-Rohling, J, Lewinshohn P, Rohde P, Seeley J, Monson CM, Meyer KA, et al. Gender differences in the suicide-related behaviors of adolescents and young adults. Sex Roles: A Journal of Research 1998; 39(11/12): 839-854.

19. Heiser NA, Turner SM, Beidel DC. Shyness: Relationship to social phobia and other psychiatric disorders. Behav Res Ther 2003; 41: 2009-2021.

20. Goodman E, Adler NE, Kawachi I, Frazier L, Huang B, Colditz GA. Adolescents' perceptions of social status: Development and evaluation of a new indicator. Pediatrics 2001; 108(2): E31. URL: http//www.pediatrics.org/cgi/content/full/108/2/e31 (Accessed on June 26, 2008).

21. Grunbaum JA, Kann L, Kinchen K, Ross J, Hawkins J, Lowry R. Youth Risk Behavior Surveillance-United States, 2003. MMWR 2004; 53(SS-2): 1-29.

22. Kolbe LJ, Kann L, Collins J. Overview of the Youth Risk Behavior Surveillance System. Public Health Rep 1993; 108: 2-10.
23. Brener ND, Collins JL, Kann L, Warren Cw, Williams BI. Reliability of the youth risk behavior survey. Am J Epidemiol 1995; 141(6): 575-580.

24. Brener ND, Kann L, McManus T, Kinchen SA, Sundberg EC, Ross JG. Reliability of the 1999 Youth Risk Behavior Survey questionnaire. J Adolesc Health 2002; 31 : 336-342.

25. Cole TJ, Bellizzi MC, Flegal KM, Dietz WH. Establishing a standard definition for child overweight and obesity worldwide: International survey. BMJ 2000; 320: 1-6.

26. Mechanic D, Hansell HR. Adolescent drug use, psychological well-being, and self assessed physical health. J Health Soc Behav 1987; 28: 364-374.

27. Vingilis E, Wade TJ, Adlaf E. What factors predict student self-rated physical health? J Adolesc 1998; 21: 83-97.

28. Tremblay S, Dahinten S, Kohen D. Factors related to adolescents' self-perceived health. Supplement to Health Reports (Statistics Canada Catalogue 82-003-SPE) 2003; 14: 7-16.

29. Stravynski A, Boyer R. Loneliness in relation to suicide ideation and parasuicide: A population-wide study. Suicide Life Threat Behav 2001; 31(1): 32-40.

30. Thompson EA, Mazza JJ, Herting JR, Randell BP, Eggert, LL. The mediating roles of anxiety, depression, and hopelessness on adolescent suicidal behaviors. Suicide Life Threat Behav 2005; 35(1): 14-34.

31. Aaronio M, Winter T, Kujala U. Associations of health-related behaviour, social relationships, and health status with persistent physical activity and inactivity: A study of Finnish adolescent twins. Br J Sports Medicine 2002; 35(5): 360-364.

32. Dowdle EB, Santucci ME. Health risk behavior assessment: Nutrition, weight, and tobacco use in one urban seventh-grade class. Public Health Nurs 2004; 21 : 128-136.

33. Goodwin DK, Knol LL, Eddy JM, Fitzhugh EC, Kendrick OW, Donahue RE. The relationship between self-rated health status and the overall quality of dietary intake of U.S. adolescents. J Am Dent Assoc 2006; 106: 1450 .

34. Tremblay MS, Wilms JD. Is the Canadian childhood obesity epidemic related to physical inactivity? Int $\mathrm{J}$ Obes 2003; 27: 1100-1105.

35. Fredriksen K, Rhodes J, Reddy R, Way N. Sleepless in Chicago: Tracking the effects of adolescent sleep loss during the middle years. Child Dev 2004; 75(1): 8495 . 
36. Wolfson AR, Carskadon MA. Sleep schedules and daytime functioning in adolescents. Child Dev 1998; 69: 875-887.

37. Zullig K, Ubbes VA, Pyle J, Valois RF. Self-reported weight perceptions, dieting behavior, and breakfast eating among high school adolescents. J Sch Health 2006; 76(3): 87-92.
Address for correspondence: Randy M. Page Department of Health Science 221 Richards Building Brigham Young University Provo, Utah, 84602 USA

Tel.: 801-422-1131

Fax: 801-422-0273

E-mail: randy_page@byu.edu 